\title{
CARTAS ABIERTAS A DOS AMIGOS, UN ECONOMISTA AUSTRIACO Y UNO SOCIALISTA*
}

Geoffrey $M$. Hodgson

" DOI: https://doi.org/10.18601/01245996.v21n40.04. Tomado de Hodgson (2018, cap. 10). Traducción de Alberto Supelano. Se publica con las autorizaciones correspondientes. Recepción: 05-06-2018, aceptación: 30-10-2018. Sugerencia de citación: Hodgson, G. (2019). Cartas abiertas a dos amigos, un economista austriaco y uno socialista. Revista de Economía Institucional, 21(40), 111-142.

a Profesor investigador de Ciencias Empresariales Universidad de Hertfordshire, Reino Unido, [g.m.hodgson@herts.ac.uk], [https://orcid.org/00000002-5823-3996] 


\section{Cartas abiertas a dos amigos, un economista austriaco y uno socialista}

Resumen. Dirijo estas cartas dos amigos imaginarios. En la primera, a un libertario de libre mercado, reconozco las fortalezas de su posición, pero argumento que la posición libertaria básica se debe actualizar a la luz de los desarrollos del mundo financiero y corporativo, y de la creciente desigualdad en la distribución de la riqueza. Dirijo la segunda carta a un socialista, que aún desea maximizar la propiedad pública y minimizar los mercados. Argumento que esta posición ha recibido golpes fatales en el siglo XX, provenientes de la crítica teórica y de catástrofes prácticas. El socialismo -al menos en su sentido clásico- ha muerto como doctrina práctica y humana. No así el Estado de bienestar, quizás con un sector público significativo. El debate se refiere a la dirección que nos gustaría que tomara el capitalismo.

Palabras clave: economía austríaca, libre mercado, Hayek, von Mises, capitalismo, socialismo, Estado de bienestar; JEL: A12, B13, B14, B24, B25, H11, H82.

\section{Two open letters to friends, an austrian economist and a socialist}

Abstract. I address these letters two imaginary friends. In the first, to a free-market libertarian, I recognize the strengths in her position but argue that the basic libertarian stance needs to be updated in the light of developments in the financial and corporate world, and of growing inequalities in the distributions of wealth. The second letter is to a socialist, who still wishes to maximize public ownership and minimize markets. I argue that this position has received fatal blows in the twentieth century, from theoretical critiques and from practical catastrophes. Socialism -at least in its classic sense- is dead as a practical and humane doctrine. The welfare state, perhaps also with a significant public sector, is not. The real debate concerns what direction we would wish to take capitalism.

Keywords: Austrian economy, free market, Hayek, von Mises, capitalism, socialism, welfare state; JEL: A12, B13, B14, B24, B25, H11, H82.

\section{Cartas abertas a dois amigos, um economista austríaco e um socialista}

Resumo. Dirijo estas cartas para dois amigos imaginários. Na primeira, a um libertário do livre mercado, reconheço os pontos fortes de sua posição, mas defendo que a posição libertária básica deve ser atualizada à luz do desenvolvimento do mundo financeiro e corporativo, e da crescente desigualdade na distribuição de riqueza. Dirijo a segunda carta a um socialista, que ainda quer maximizar a propriedade pública e minimizar os mercados. Argumento que essa posição recebeu golpes fatais no século $\mathrm{XX}$, vindos da crítica teórica e de catástrofes práticas. $\mathrm{O}$ socialismo - pelo menos no seu sentido clássico - morreu como doutrina prática e humana. Não é assim o estado de bem-estar, talvez com um setor público significativo. O debate se refere à direção que gostaríamos que o capitalismo tomasse.

Palavras-chaves: economia austríaca, livre mercado, Hayek, von Mises, capitalismo, socialismo, estado de bem-estar; JEL: A12, B13, B14, B24, B25, H11, H82. 
Vi las costumbres de mi tiempo y publiqué estas cartas. Jean-Jacques Rousseau, Julie, ou la Nouvelle Helö̈se (1761)

耳 $\mathrm{n}$ el siglo XVIII estuvo de moda exponer un argumento político Como una carta a un destinatario real o imaginario. Esta forma epistolar fue utilizada por Edmund Burke, Thomas Paine y Mary Wollstonecraft. En el prólogo a Julie de Jean-Jacques Rousseau, un interrogador ficticio preguntaba si las cartas de la novela eran ficticias o reales. Se puede hacer la misma pregunta sobre las siguientes. Puedo pensar en varias personas a quienes sería apropiado enviárselas. Elegí esta forma, una carta a un libertario y la otra a un izquierdista, principalmente porque me permite triangular mi propia posición sobre diversos temas.

\section{QUERIDO DULCE LIBERTAD}

Desde los años setenta, las opiniones libertarias pro mercado con las que te identificas gozan de una gran reanimación. Solían ser objeto de burla. Hoy son predominantes. Pero han sido mal entendidas.

Algunos sugieren erróneamente que toda oposición de libre mercado al socialismo debe ser conservadora o fascista. Pero nunca consideré que tu doctrina libertaria pro mercado fuese conservadora o fascista. Los valores libertarios y liberales clásicos están en fuerte oposición al fascismo y a los valores conservadores que socavan los derechos individuales u otorgan privilegios especiales.

Pero algunos de tus líderes mancharon su reputación flirteando con dictaduras. En un libro publicado por vez primera en 1927, Ludwig von Mises elogió el fascismo como "un arreglo provisional" que "ha salvado por el momento a la civilización europea". No se puede excusar esta breve declaración, pese a que figuraba en un libro de otro modo dedicado a promover valores liberales clásicos, y que von Mises era un judío que al final tuvo que escapar de los nazis. De 1932 a 1934 von Mises continuó como asesor económico en Austria, incluso para el gobierno austro-fascista o "fascista clerical" del Canciller Engelbert Dollfuss, quien asumió poderes dictatoriales, cerró el Parlamento, destruyó los sindicatos y prohibió varios partidos políticos. Esto no significa que von Mises fuera fascista, pero otros economistas habrían puesto límites para asesorarlos ${ }^{1}$.

La idea de que las dictaduras transitorias a veces pueden ser necesarias, así sean asesinas, se transmitió a su discípulo Friedrich Hayek.

${ }^{1}$ Ver von Mises (1985, pp. 47, 51). Dollfuss fue asesinado por agentes nazis en 1934. 
Hayek argumentó que la democracia, si bien es deseable, puede ser prescindible temporalmente, en especial para defender la propiedad privada. Creía que la democracia y la libertad vendrían después, una vez se aseguraran los derechos de propiedad. Pero estas consecuencias no son automáticas: hay muchos regímenes opresivos y antidemocráticos que mantienen la propiedad privada.

Augusto Pinochet puede haber salvado los derechos de propiedad en Chile. Pero impuso una dictadura atroz que torturó a unos treinta mil civiles y asesinó a más de tres mil. El derecho a la vida y a no ser torturado es existencialmente más básico y, por tanto, más importante que el derecho a la propiedad. Hayek visitó el Chile de Pinochet y no condenó estos abusos atroces de los derechos humanos. Inspiró y condonó silenciosamente a Pinochet. Su silencio sobre los abusos de los derechos humanos básicos no se puede excusar por su edad: en los años setenta Hayek aún publicaba libros importantes ${ }^{2}$.

Me opongo al socialismo clásico porque inadvertidamente aplasta los derechos humanos y lleva a la dictadura. Von Mises y Hayek toleraron (temporalmente) algunas dictaduras y la supresión de algunos derechos humanos básicos, incluidos los de hábeas corpus y a no ser torturado. Mientras que los liberales anteriores hacían énfasis en los derechos humanos, los derechos de propiedad y la democracia, en su reacción contra el socialismo von Mises y Hayek parecían elevar el derecho de propiedad sobre todos los demás. Pero los derechos de propiedad privada requieren la protección de todos los propietarios, actuales o potenciales, contra la tortura o el exterminio. Los derechos humanos básicos y la democracia son esenciales, así como el derecho a la propiedad privada.

Es cierto que, por razones morales y prácticas, el principio democrático del gobierno de la mayoría no puede tener libre dominio sobre

2 Ver Hayek (1960, 1973, 1979). Caldwell y Montes (2015) hacen un recuento detallado de la relación de Hayek con el régimen de Pinochet. Milton Friedman también visitó el Chile de Pinochet. Pero, a diferencia de Hayek y Margaret Thatcher, Friedman (1991) declaró: "Nada bueno tengo que decir del régimen político impuesto por Pinochet. Fue un régimen político terrible". Friedman (1976) sostuvo que solo daba “consejos técnicos” y expresó su "profundo desacuerdo con el sistema político autoritario de Chile". Después afirmó que creía que la promoción de mercados libres en Chile acabaría socavando la dictadura de Pinochet. Pero Letelier (1976) alegó que los economistas de Chicago financiados por la CIA se reunieron con los generales antes del golpe y les dieron cierta apariencia de legitimidad académica, así como préstamos del Banco Mundial cuando llegaron el poder. Klein (2007) y Schliesser (2010) documentan y analizan la participación de Friedman y sus colegas de Chicago en el asesoramiento de Pinochet.

Revista de Economía Institucional, vol. 2 i, n. ${ }^{\circ} 40$, Enero-junio/20i9, Pp. ili-i 42 ISSN OI 24-5996/E-ISSN 2346-2450 
todo, especialmente en lo que se refiere a los derechos humanos. $\mathrm{Si}$ los derechos son inalienables, no pueden ser eliminados por ningún voto. Pero esto no justifica una dictadura brutal.

La primera ministra del Reino Unido Margaret Thatcher afirmó que era una de tus hermanas ideológicas. En 1999 agradeció al ex dictador Pinochet por "llevar la democracia a Chile". Es claro que al dirigirse a alguien que en 1973 derrocó un gobierno elegido democráticamente, invistió al término democracia un significado thatcheriano esotérico. En realidad, Pinochet fue un torturador y un asesino ${ }^{3}$.

Thatcher también auspició el apartheid en Sudáfrica. En 1987 declaró que el Congreso Nacional Africano, liderado por Nelson Mandela, era "una organización terrorista típica". Y continuó: "Quien piense que va a dirigir el gobierno en Sudáfrica vive en las nubes". Subestimó el liderazgo inteligente, indulgente y humano de Mandela ${ }^{4}$.

De manera similar, en 1986 el presidente de Estados Unidos Ronald Reagan vetó un proyecto de ley del Congreso que habría impuesto sanciones al régimen del apartheid en Sudáfrica. Después de asumir el cargo en 1981, Reagan propuso revocar un embargo de armas que el ex presidente Jimmy Carter impuso a Guatemala por sus pésimos antecedentes en derechos humanos. Reagan financió escuadrones de la muerte en Nicaragua y apoyó dictaduras en Argentina, Brasil, Chile y otros países.

¿Protestaste entonces? No oí muchas voces de tu cofradía. La mayoría de las protestas vino de la izquierda. El silencio de tus cofrades fue mortal. Ayudó a asociar el libertarismo pro mercado con la Derecha.

Libertarios prestigiosos apoyaron algunas dictaduras porque defendían la propiedad privada. Pero defender los derechos de propiedad no es excusa para pisotear otros derechos humanos. Los escuadrones de la muerte y los torturadores no son de ningún modo absueltos cuando defienden la propiedad privada de los ricos.

Igual que tú, deseo diferenciar el libertarismo pro mercado del apoyo a las dictaduras. Este no se deriva necesariamente del primero. Igual que tú, me opongo a todas las dictaduras y apoyo la democracia y los derechos humanos, incluido el derecho a la propiedad.

${ }^{3}$ Ver BBC News (1999).

${ }^{4}$ Ver Bevins y Streeter (1996). En 1976, Pinochet ordenó el asesinato de Orlando Letelier, ministro del antiguo régimen democrático elegido en Chile, que había huido a Estados Unidos. Dos personas murieron por la explosión del coche bomba en Washington, DC (Franklin, 2015). En un intento de encubrir su culpabilidad, Pinochet ordenó que el agente encargado del asesinato también fuera asesinado. 
A pesar de sus deficiencias políticas, la crítica teórica a la planeación socialista colectivista de von Mises y Hayek es uno de los logros intelectuales más importantes del siglo $\mathrm{XX}^{5}$. Ellos demostraron concluyentemente que al marginar a la empresa privada y a los mercados, las economías socialistas reprimirían la innovación y el progreso técnico y amenazarían las libertades. La experiencia de los regímenes de tipo soviético del siglo XX lo ha confirmado.

Aunque la Izquierda rápidamente denominó "Derecha" a todos los críticos del socialismo, esta etiqueta posicional es engañosa. Tu vertiente libertaria se remonta a los revolucionarios franceses, a los padres fundadores de Estados Unidos y a los Niveladores ingleses. Si eres un libertario democrático, eres entonces parte legítima de la Izquierda original ${ }^{6}$.

Pero esa es tu fortaleza y tu problema. Luego explicaré por qué. Doy más importancia que tú al problema de la desigualdad en el capitalismo. No valoro menos la libertad, pero creo que el Estado tiene un papel más importante y necesario del que tú imaginas en la protección de la libertad y en el logro de la prosperidad.

Así como tus cofrades mostraron que la planificación socialista totalmente colectivista era inviable, la utopía del mercado libre, donde todo se negocia como propiedad, es también inviable. Además, ignora los principales desarrollos de las economías capitalistas modernas que analizaré más adelante.

No es casual que tus principios básicos fueran promovidos por los Niveladores de la década de 1640, los revolucionarios estadounidenses de la década de 1770 y la Izquierda francesa de la década de 1790. Aparte de los grandes terratenientes, las economías de mercado francesa e inglesa estaban entonces dominadas por pequeños productores, desde campesinos hasta pequeños fabricantes. Estados Unidos fue al inicio un país de pequeños agricultores y comerciantes. Los discursos de esas épocas sobre la libertad, la propiedad, el comercio y contra los monopolios aludían al mundo del productor a pequeña escala.

Eran anteriores al ascenso del capitalismo industrial, que aumentó la necesidad económica de una educación masiva organizada, de

${ }^{5}$ Aunque se puede considerar a Hayek como un libertario, en su pensamiento había fuertes elementos de conservatismo burkeano. Hayek destacó la importancia de la experimentación cuidadosa en el diseño institucional y argumentó -igual que Burke- que las instituciones son depósitos de enorme conocimiento complejo o tácito que no puede entender un solo individuo.

${ }^{6}$ Los lectores perplejos por esta afirmación deben consultar Hodgson (2018, cap. 2) y su discusión de los orígenes de los términos Izquierda y Derecha, así como la gráfica 7.1 .

Revista de Economía Institucional, vol. 2 i, N. ${ }^{\circ}$ 40, enero-junio/2oig, Pp. ili-il42 ISSN OI $24-5996 / \mathrm{E}-$ ISSN $2346-245^{\circ}$ 
seguridad social y atención a la salud, así como de regulaciones y burocracias para asegurar que los mercados funcionaran eficazmente y se protegiera a los consumidores. Todo esto requería impuestos más altos y un Estado más grande.

Ahora tenemos un capitalismo ensombrecido por enormes corporaciones. Coordinado por un sistema financiero global dominado por grandes bancos y gigantescas instituciones financieras. La deuda es hoy un producto básico importante, y las burbujas de activos basadas en la deuda son los principales desestabilizadores potenciales del sistema. Hoy, gran parte de la producción es de servicios y no de bienes físicos. Buena parte de la propiedad consiste en propiedad intelectual u otra propiedad intangible. La información desempeñó un papel esencial en todas las economías anteriores, pero en las economías altamente complejas del siglo XXI, todo depende del procesamiento continuo de vastas y crecientes cantidades de información muy diversa, a escala global. Estos desarrollos colosales cuestionan tu visión de la economía propia del siglo XVIII y plantean nuevas preguntas sobre la libertad, la propiedad y el papel del Estado.

Sé que tú y muchos de tus compañeros libertarios protestarían contra el poder oligopólico, y que exiges mayor competencia. Pero no has prestado suficiente atención al hecho de que, a menos que existan medidas compensatorias, los grandes jugadores en mercados competitivos siempre intentarán crear nichos u oligopolios $\mathrm{y}$, por tanto, concentrarán su poder económico. Intentarán protegerse contra la competencia por esos medios. E1 capitalismo ha mostrado persistentes tendencias innatas al oligopolio.

La reacción de von Mises y Hayek ante el crecimiento de la gran corporación fue inadecuada e irrealista. Von Mises consideraba que la separación entre propiedad y control era ineficiente, anticompetitiva y resultado de la intrusión del gobierno. Hayek culpó igualmente al Estado por la existencia de grandes corporaciones; como si el Estado fuese siempre responsable de lo que sale mal. Sin duda, las legislaturas estatales han cumplido el papel principal en el desarrollo de la forma legal de la corporación. Pero también han intervenido en la constitución legal de la propiedad, de los mercados y de empresas más pequeñas, todo lo cual das por sentado ${ }^{7}$.

Tus mentores ignoraron otras fuentes de poder oligopólico y anhelaban el retorno a una economía individualista de pequeños productores y empresarios. Subestimaron las enormes economías de

7 Ver, p. ej., von Mises (1949, p. 307) y Hayek (1948, p. 116). Para un examen crítico, ver también Hodgson (2015). 
escala de algunas unidades económicas a gran escala. Nunca enfrentaron adecuadamente la corporación moderna y el papel dinámico que a menudo desempeñó en el desarrollo del capitalismo y de la tecnología moderna.

Von Mises y Hayek favorecieron un sistema dominado por la propiedad privada y el intercambio contractual. Pero su descripción de estas vitales características institucionales era inadecuada. No distinguían entre propiedad y posesión. La propiedad implica derechos legales establecidos por instituciones legislativas y judiciales. En cambio, al adoptar nociones sumamente amplias y vagas del mercado y del intercambio, von Mises consideró que la propiedad era algo que se "tenía" de facto: el control de los servicios que presta un bien, eliminando de la noción de propiedad la cuestión de los derechos legales. Aunque los derechos de propiedad eran esenciales en su argumento, su comprensión de ellos era defectuosa. $\mathrm{Ni}$ el uno ni el otro reconocieron el papel del Estado en la constitución y el mantenimiento de los derechos de propiedad. Una economía de empresa privada requiere un Estado efectivo y un sistema jurídico estatutario para sostenerla ${ }^{8}$.

La definición de intercambio de von Mises también era demasiado amplia y vaga. Para él, toda acción, incluso la de un individuo aislado, era "intercambio"; así ignoró el intercambio de derechos y obligaciones legales. Von Mises también adoptó una definición cuasi universal del mercado: "el sistema social de la división del trabajo bajo propiedad privada de los medios de producción”. Describió toda economía con división del trabajo, donde la producción estaba vagamente bajo algún control "privado", como una economía de "mercado", sin mencionar los contratos legales ni la propiedad legal ${ }^{9}$.

Estos criterios laxos se podrían aplicar a casi todas las formaciones sociales de la historia humana. No hacen una distinción conceptual entre intercambios comerciales y no comerciales, como por ejemplo entre prostitución y sexo consensual. En general, los argumentos positivos de los economistas austriacos en favor de la propiedad privada y los mercados se vieron debilitados por una grave disolución del significado de esos términos. Sus conceptos de propiedad, intercambio y mercado fueron vaciados de contenido. La casi ubicuidad de sus definiciones los despojó de gran parte de su significado. Carecían de conceptos adecuados para entender la economía de mercado que favorecían.

${ }^{8}$ Ver von Mises (1981, p. 27). E1 papel del Estado en la constitución y la protección de la propiedad se discute en Hodgson (2015).

${ }^{9}$ Ver von Mises (1949, pp. 97, 257).

Revista de Economía Institucional, vol. 2 i, N. ${ }^{\circ}$ 40, enero-junio/2oig, Pp. ili-il42 ISSN OI $24-5996 / \mathrm{E}-$ ISSN $2346-245^{\circ}$ 
Promueves correctamente el Estado de derecho, pero la noción de derecho adoptada por algunos de tus mentores es inadecuada. $\mathrm{Ha}-$ yek, por ejemplo, redujo el derecho a la costumbre. Su interpretación evolutiva del derecho, como una búsqueda experimental de principios universales de justicia, restó importancia a la necesidad de un fuerte poder compensatorio. Hayek confió muy a menudo en exhortaciones a la libertad individual y al Estado de derecho, y prestó poca atención a las relaciones de poder necesarias para preservarlos. El poder compensatorio debe ser legítimo incluso a ojos del Estado, y suficientemente independiente y poderoso para que se aplique, aun contra los ricos y poderosos que yerran en la política o en los negocios ${ }^{10}$.

En el gran debate del siglo XX sobre capitalismo versus socialismo, ambas partes prestaron insuficiente atención a las normas y estructuras legales: no caracterizaron apropiadamente los sistemas rivales. Los defensores del socialismo emplearon modelos de equilibrio general que supuestamente se ajustaban a todos los mundos; ignoraron características esenciales, específicas e institucionales del capitalismo y del socialismo. Von Mises y Hayek especificaron inadecuadamente el carácter de la propiedad privada y del intercambio, convirtiéndolos en fenómenos casi universales. Ninguna de las partes consideró las instituciones más específicas que contribuyeron al dramático despegue económico del capitalismo alrededor de 1800.

Una de las principales contribuciones positivas de tus mentores fue centrar la atención en la naturaleza y el papel central del conocimiento en la economía. Subrayaron que el conocimiento es localizado, a menudo tácito y disperso, y que no se puede comunicar fácilmente a un gran órgano colectivo. Tenían una concepción mucho más sofisticada del carácter del conocimiento que sus adversarios, que intentaron usar modelos neoclásicos irrealistas para defender el socialismo ${ }^{11}$.

Pero tus mentores subvaloraron notablemente el grado en que la transferencia contractual de información tiene algunas caracte-

${ }^{10}$ Sobre el derecho, ver Hayek (1973) y la crítica de Hodgson (2015). Fukuyama (2011, cap. 17) da una buena explicación de los orígenes y del carácter del Estado de derecho. Sobre el poder compensatorio, ver Galbraith (1962, 1969), Moore (1966), North, Wallis y Weingast (2009), y Hodgson (2015).

${ }^{11}$ Por "neoclásico" aquí me refiero al enfoque general de la teoría económica que fue dominante durante la mayor parte del siglo $\mathrm{XX}$, que involucra el análisis de equilibrio y agentes que maximizan la utilidad. Aún predomina en los manuales estándar. Samuelson (1947) popularizó esta designación y fue un gran exponente de este enfoque. La economía neoclásica tiene variantes de equilibrio general (walrasiano) y de equilibrio parcial (marshalliano). 
rísticas curiosas que cuestionan la visión estándar del contrato y del intercambio.

Primera, una vez la adquiere el comprador, la información codificable a menudo se puede reproducir fácilmente en copias múltiples, y posiblemente vender a otros. Esto puede poner en desventaja al vendedor. Por ello, puede haber licencias, patentes u otras restricciones para impedir que el comprador la venda. Segunda, la información codificable tiene la propiedad peculiar de que, una vez se vende, también queda en manos del vendedor. No es una mercancía "normal" que cambia de manos del vendedor al comprador cuando se compra. Tercera, como el Nobel Kenneth Arrow escribió: "hay una paradoja fundamental en la determinación de la demanda de información: su valor para el comprador no se conoce mientras no tenga la información, pero entonces la ha adquirido sin un costo". Si conociéramos lo que vamos a comprar no necesitaríamos comprarlo ${ }^{12}$.

De modo que en una economía que involucra considerables intercambios de información, a veces es difícil o incluso contraproducente seguir el consejo de Hayek y establecer "reglas claras que, sobre todo, permiten distinguir entre lo mío y lo tuyo". La información desafía los límites de la propiedad exclusiva e individual. No siempre se puede definir claramente lo que se posee, porque definirlo completamente es regalarlo. No siempre es posible o eficiente dividir la información en partes discretas y poner a cada cual una etiqueta de propiedad. A menudo es difícil determinar quién descubrió inicialmente la información, o quién puede reclamar el título legal de su propiedad. Una sociedad rica en información cuestiona el significado y los límites de lo que es mío y lo que es tuyo ${ }^{13}$.

La información es un bien no rival que a menudo se puede compartir fácilmente. Que la use una persona no impide que la use otra. Pero la propiedad privada de los activos intelectuales implica concentraciones exclusivas de derechos y la negación general a otros de los derechos de usuario. Pero tales derechos de propiedad exclusivos son necesarios para que los activos de información se usen como garantía. Tu lógica pro mercado requiere que el conocimiento se privatice. Pero la negación resultante de los beneficios adquiridos a bajo precio de la posesión compartida de activos de información no rivales puede generar notables ineficiencias.

La planeación y la competencia en el mercado funcionan con la menor dificultad cuando hay numerosas mercancías de tipo similar.

12 Ver Nelson (1959) y Arrow (1962, p. 616).

${ }^{13}$ Ver Hayek (1948, p. 18).

Revista de Economía Institucional, vol. 2 i, n. ${ }^{\circ} 40$, Enero-junio/20i9, Pp. ili-i 42 ISSN OI 24-5996/E-ISSN 2346-2450 
Pero los días de la producción de adminículos se fueron. En las economías desarrolladas modernas predominan servicios muy variados, $\mathrm{y}$ muchos bienes físicos son sumamente complicados. Hay mucho más procesamiento de información compleja. Cada transacción en cada economía siempre ha sido única, pero hoy, en el capitalismo, cada transacción individual es más distintiva e idiosincrásica. La entrega de cada servicio varía en tiempo y según el contexto, a veces en alto grado. Como los servicios detallados y delicados de un cuidador doméstico o una enfermera, o los diversos y variados contenidos de periódicos o libros.

En una economía compleja, no de adminículos, la planificación central general y detallada de tales servicios es imposible. Pero, aunque la competencia en el mercado pueda seguir siendo un estímulo para la eficiencia y la innovación, tampoco puede minimizar fácilmente los precios como sugieren los libros de texto estándar. Estas complejidades han generado un papel adicional importante para el Estado, no en la planificación central sino en la fijación de estándares de comercio y en la regulación de los mercados.

Además, la extensión y subdivisión infinitas de la propiedad en una economía del conocimiento densamente interconectada puede crear "anticomunes", donde los derechos interconectados obstaculizan la inversión y el comercio. Este problema se presenta particularmente en las patentes y otros tipos de propiedad intelectual, y se ha vuelto más agudo en las economías cada vez más intensivas en conocimiento. La imposición ubicua de normas legales "para distinguir entre lo mío y lo tuyo" puede privar a muchas personas de información esencial para su trabajo o su bienestar. El capitalismo se ve desafiado por la creciente intensidad del conocimiento: para sobrevivir, debe limitar su propio uso de la propiedad privada y del mecanismo de mercado ${ }^{14}$.

A medida que el capitalismo se ha vuelto más complejo, estas necesidades informativas se han hecho mucho mayores, lo que implica una mayor necesidad de suministro público junto con un sector privado pujante. Si bien mucha información y muchos conocimientos no se pueden compartir (debido a su carácter tácito, a dificultades de interpretación o a que son inaccesibles), otra gran parte sí se puede compartir, y esto puede ser de gran valor productivo. En consecuencia, los beneficios del suministro privado y contractual de información

14 Ver Heller (2008) y Pagano (2014). Polanyi (1944) argumentó que el capitalismo emergente limitó el papel del mercado para evitar la disolución del tejido social. Aquí el argumento es diferente: la naturaleza de la información pone límites al mecanismo de mercado. 
pueden ser mucho menores que los costos de oportunidad totales de cobrar un precio por usarla. Un sistema de mercado saludable depende de que los mercados de información sean incompletos; algunos datos cruciales no deben tener dueño y deben ser de acceso gratuito.

Consideremos el fenomenal crecimiento de internet. A comienzos de los años noventa, la Organización Europea para la Investigación Nuclear (CERN) desarrolló elementos clave de la infraestructura de internet. Los lanzó gratuitamente al público, para asegurar que la tecnología de la información se generalizara. Del mismo modo, muchos programas de computador e incluso sistemas operativos son de acceso gratuito. Internet ha estimulado notablemente los mercados, pero no todos sus componentes o facilitadores se comercializaron. El capitalismo moderno ha reducido casi a cero el costo marginal de muchos bienes y servicios informativos adicionales, lo que los hace casi gratuitos y abiertos a modos de distribución distintos del mercado ${ }^{15}$.

Para evaluar lo que se compra, especialmente en un capitalismo tecnológicamente complejo, la elección efectiva del consumidor suele requerir algún conocimiento científico y técnico. Por tanto, en una economía de mercado, la elección informada requiere una educación pública efectiva en ciencia. Este problema fue abordado por pensadores liberales como John Dewey, para quien la educación y la democracia facilitaban el debate público sobre la ciencia y sus objetivos ${ }^{16}$.

Aunque la intervención del Estado en la economía a menudo se confunde con problemas de complejidad y conocimiento distribuido, el Estado a veces puede intervenir eficazmente como coordinador, facilitador, procesador de información y líder estratégico. Como dijo Hayek: "Lo importante es el carácter más que el volumen de actividad del gobierno" 17 .

Tus mentores exponen una teoría del dinero y las finanzas más adecuada para el siglo XVII que para el siglo XXI. Esta trata el dinero principalmente como una mercancía que sirve de medio de cambio y subestima el papel crucial del Estado en el desarrollo de los sistemas financieros modernos, que involucran la compra y la venta de deuda.

15 Ver Rifkin (2014).

16 Ver Dewey (1916, 1935, 1938, 1939), Ryan (1995), Evans (2000), y Hodgson (2013, cap. 10).

${ }^{17}$ Ver Hayek (1960, p. 222). Sobre el papel económico del Estado, ver Nelson (1981, 2003), Kenworthy (1995), Chang (1997, 2002), Evans y Rauch (1999), Reinert (2007), Martinez (2009) y Mazzucato (2013). 
Tu teoría está mal equipada para tratar la inestabilidad innata del capitalismo y el crecimiento de enorme instituciones financieras ${ }^{18}$.

Tus mentores hicieron una poderosa crítica de la planificación centralizada integral pero dieron pocos consejos prácticos detallados para la reforma o el desarrollo dentro del capitalismo, aparte de privatizar las empresas públicas, promover la competencia, minimizar la regulación externa y reducir la escala y los poderes del Estado al mínimo práctico. Estos son eslóganes, no políticas detalladas y prácticas.

Tus mentores no lograron consolidar su victoria en el debate sobre el cálculo socialista y desarrollar los fundamentos de una política práctica. Al rechazar la "economía mixta" o cualquier otra posición intermedia, se fueron a un extremo y cumplieron un papel ideológico en vez de un papel práctico detallado para los políticos o diseñadores de política. Al perseguir los imperativos del mercado sin restricciones, no explicaron por qué se debía mantener una institución ajena al mercado como la familia.

Pero Hayek y otros entendieron que una economía de libre mercado no puede funcionar cuando las personas carecen de educación y de los bienes necesarios para sobrevivir como agentes económicos. Por ello, abogó por una legislación que limitara las horas de trabajo, por el apoyo estatal a la seguridad social y la atención en salud, por la educación y la investigación financiadas por el Estado, por un ingreso básico garantizado y otras medidas de bienestar. Hayek también propuso una estrategia gubernamental anticíclica de tipo keynesiano para enfrentar las fluctuaciones de la actividad económica ${ }^{19}$.

Pero ignoró los mecanismos que generan mayor desigualdad en el capitalismo corporativo moderno. Estos incluyen los beneficios de la propiedad de activos que pueden servir de garantía, incluida la propiedad tangible e intangible. Se inclinó por la socialdemocracia en algunos aspectos, pero descuidó por completo el problema de las crecientes desigualdades en la distribución de la riqueza ${ }^{20}$.

Tus amigos libertarios pueden descartar esas preocupaciones por la desigualdad como producto de la envidia. Pero aun si suponemos que todos los ingresos reflejan esfuerzo y capacidad, subsiste una enorme desigualdad de la riqueza. Gran parte de la desigualdad de la riqueza

18 Ver por ejemplo Keynes (1930, 1936), Minsky (1982, 1986), Ingham (2004, 2008) y Wray (2012).

19 Sobre las opiniones supuestamente "social demócratas" de Hayek, ver Hoppe (1994), Block (1996), Rodrigues (2012) y Hodgson (2015, cap. 12).

${ }^{20}$ Sobre los procesos que generan desigualdad en el capitalismo ver Piketty (2014) y Hodgson (2015, cap. 15). 
que se observa en las sociedades capitalistas se debe a desigualdades de la herencia ${ }^{21}$.

Las desigualdades extremas en la distribución de la riqueza son injustas y disfuncionales. Socavan los principios de simpatía y solidaridad de los que depende toda sociedad. Como argumentó el filósofo John Finnis: "lo que es injusto respecto de las grandes disparidades de riqueza en una comunidad no es la desigualdad como tal, sino el hecho de que [...] los ricos no han redistribuido esa parte de su riqueza que otros podría usar mejor para realizar los valores básicos en su propia vida ${ }^{22}$.

Se puede justificar cierta redistribución de la riqueza con base en una mayor satisfacción de las necesidades humanas, incluida la necesidad de educación generalizada y de desarrollo personal. Por ejemplo, tú favoreces la iniciativa empresarial: la redistribución moderada de la riqueza puede brindar la oportunidad de ser empresario a un mayor número de personas.

Tu oposición general a los sindicatos es también injustificada. Ignoras el hecho de que el trabajo y el capital son fundamentalmente diferentes, y que nunca pueden unirse en igualdad de condiciones. E1 propietario de capital puede hacer dinero mientras está de vacaciones en las Islas Caimán, mientras que el propietario de trabajo está obligado a estar presente cuando y donde se contrata su trabajo.

El propietario de capital puede usar esos activos como garantía para pedir dinero en préstamo e invertirlo en proyectos lucrativos. Sin esclavitud, el trabajo no se puede utilizar como garantía, y el trabajador asalariado no puede usar su capacidad de trabajo como garantía para obtener un préstamo asegurado. Debido a estas asimetrías, los sindicatos pueden cumplir un papel importante para atenuar el desbalance. Como señaló John Kenneth Galbraith, los sindicatos son una importante fuente de poder compensatorio en el capitalismo moderno ${ }^{23}$.

Incluso en un sistema de productores a pequeña escala existen límites para el uso de los mercados. En general, tú favoreces los mercados sobre otros sistemas de asignación de recursos, ¿pero reconoces esos límites? ¿E1 mercado es una solución para todos los problemas? Si es así, por qué no promover la disolución del matrimonio y su sustitución por un sistema de mercado de prostitutas, de venta de bebés

${ }^{21}$ Ver Bowles y Gintis (2002) y Credit Suisse Institute of Investigation (2012).

${ }^{22}$ Ver Finnis (1980, p. 174).

${ }^{23}$ Ver Galbraith (1952, 1969). 
y de servicios domésticos contratados? Con razón no lo promueves. Pero, ¿por qué no especificas las circunstancias en que los mercados son inapropiados o no pueden funcionar, y por qué no explicas estas limitaciones? Una mejor defensa de los mercados y de la propiedad privada conocería mejor sus limitaciones.

Los mercados no pueden funcionar en todas partes, debido en parte a que dependemos de zonas de interacción íntima e interpersonal que generan confianza y trascienden el cálculo monetario del costo y la recompensa. Los sistemas de mercado siempre dependen de instituciones distintas del mercado, como la familia y el Estado. Tú ignoras el hecho de que el capitalismo nunca puede ser un sistema de mercado al ciento por ciento. Siempre habrá mercados faltantes.

Por ejemplo, un sistema de trabajo asalariado no puede en principio vincular a todos los trabajadores en contratos laborales por el resto de su vida. Esto equivaldría a la esclavitud. Bajo el capitalismo nunca pueden existir mercados de futuros completos para el trabajo.

Por tanto, como señaló el gran economista Alfred Marshall, los empleadores pueden no invertir adecuadamente en capacitación de los trabajadores por temor a que dejen su empleo y pierdan la inversión. Este es un argumento para una sustancial intervención del Estado en la formación y el desarrollo de capacidades de los trabajadores ${ }^{24}$.

Y luego está la cuestión del cambio climático. Estás en la muy mala compañía de activistas del Tea Party y negadores del cambio climático que no pueden aceptar que el mercado no es la solución a todos los problemas, o que niegan el cambio climático porque podría legitimar alguna intervención del Estado para enfrentar las amenazas contra el clima.

Por ejemplo, el conocido libertario de libre mercado Václav Klaus ha negado con insistencia que la actividad humana está llevando al cambio climático. En junio de 2007, cuando era presidente de la República Checa, escribió un artículo en el Financial Times titulado "Lo que está en riesgo es la libertad, no el clima". Allí describió las políticas que intentan enfrentar los problemas ambientales como "la mayor amenaza para la libertad, la democracia, la economía de mercado y la prosperidad [...] Esta ideología quiere remplazar la evolución libre y espontánea de la humanidad por una especie de planificación centralizada (ahora global)". Por supuesto, enfrentar el cambio climático requerirá la acción concertada de los Estados. Pero las políticas correctivas propuestas por los principales expertos en el tema están muy lejos del espantajo imaginado de la planificación

${ }^{24}$ Ver Marshall (1920, p. 565). 
centralizada global. Klaus usó la expresión intimidante "planificación centralizada" postcomunista para rechazar todo tipo de intervención del Estado para enfrentar el problema ${ }^{25}$.

Problemas tales como el cambio climático no requieren únicamente la intervención del Estado sino también el compromiso moral de muchos ciudadanos con metas y políticas que no necesariamente sirven a su estrecho interés propio. Muchos de tus asociados libertarios comparten con los marxistas la visión de que los individuos son totalmente ambiciosos y egoístas, al menos en su vida económica, y que poco se preocupan por la justicia o la moral. Como argumentó Adam Smith hace largo tiempo, esta visión de la naturaleza humana es sumamente defectuosa ${ }^{26}$.

El ejemplo del cambio climático muestra que las personas no son siempre los mejores jueces de su propio bienestar, simplemente porque muchos adultos no entienden la ciencia del clima. No aceptan la evidencia científica del calentamiento global ni las razones por las que se está convirtiendo en un grave problema. Por supuesto, puede ser políticamente peligroso suponer que una persona sabe más que otra. Pero es a veces cierto. $Y$ presumir lo contrario, que la opinión de alguien es tan buena como la de cualquier otro, llevaría a tolerar la ignorancia y la incoherencia.

Tu legítima defensa de los derechos universales y de la igualdad ante la ley no debe llevar a una evaluación ética igualmente positiva de todas las opiniones. Algunas opiniones son defectuosas. E1 desarrollo y el florecimiento humanos requieren una autoridad moral y pedagógica.

En suma, hay buenos argumentos para alejarte de tu posición de extrema Izquierda (en el sentido original), y admitir algún papel del Estado en una economía de mercado pujante. Las áreas importantes para la intervención del Estado incluyen la provisión de educación masiva gratuita o subsidiada, la provisión universal de asistencia básica a la salud como mínimo, la lucha contra las desigualdades excesivas en la distribución del ingreso y de la riqueza, y la regulación del sector financiero con medidas keynesianas para reducir la volatilidad y la inestabilidad del mercado.

El sistema financiero internacional es también inestable, como demostró el Gran Desplome de 2008. Esta es una razón para una regulación nacional e internacional más firme de los mercados financieros. Las políticas de austeridad prekeynesianas también han

${ }^{25}$ Ver Klaus (2007).

${ }^{26}$ Ver Smith (1759) y Hodgson (2013).

Revista de Economía Institucional, vol. 2 i, N. ${ }^{\circ}$ 40, enero-junio/2oig, Pp. ili-il42 ISSN OI $24-5996 / \mathrm{E}-$ ISSN $2346-245^{\circ}$ 
fracasado globalmente. Como argumentó Keynes en los años treinta, las economías no se pueden revivir recortando la demanda efectiva agregada $^{27}$.

Pero en otros aspectos importantes, estoy políticamente contigo a la Izquierda (en el sentido original de ese término) porque considero que la libertad y los derechos son fundamentales para una sociedad civilizada $^{28}$.

\section{QUERIDO Y FRATERNAL CAMARADA}

Según entiendo tu posición, abandonaste algunas de las ortodoxias de marxismo, pero aún mantienes gran parte de ese credo. Aún deseas nacionalizar varias compañías importantes y crees en la lucha de clases como motivación de la historia. Admiras a Tony Benn, y quizá apoyaste al retro marxista Jeremy Corbyn como líder del partido laborista británico. Quienes comparten tu manera de pensar abundan en los partidos de izquierda europeos. El Gran Desplome de 2008 renovó su confianza al sugerir que quizá esté cerca el final del capitalismo

Sé de dónde vienes. Yo también estuve allí. Aún comparto algunas de tus actitudes y valores básicos. A ambos nos preocupan las desigualdades extremas de ingreso y de riqueza, la pobreza y la indigencia, los bajos salarios, las espantosas condiciones de trabajo, la falta de acceso a una buena educación, la inadecuada provisión de asistencia a la salud, la discriminación por raza, género, sexualidad o creencias, la devastación del planeta por corporaciones o gobiernos despreocupados, la amenaza del cambio climático y las guerras ilegales o injustificadas.

Ambos afirmamos ser demócratas y protectores de las libertades y los derechos humanos. Pero a partir de ahí empiezan nuestras diferencias. Tus aliados a veces argumentan que derechos como la libertad de expresión no son prioritarios, en especial para quienes pasan hambre y carecen de refugio o asistencia a la salud adecuados. Tienes razón al dar prioridad a las necesidades humanas más fundamentales. Pero otros derechos siguen siendo vitales. Tienen valor intrínseco: son esenciales para el florecimiento humano. También son parte de una constelación de libertades y poderes autónomos que son importantes para una economía dinámica e innovadora.

Dices que estás a favor de los derechos humanos. Pero no creo que prestes suficiente atención a las condiciones político-económicas necesarias para respaldar los derechos humanos y la democracia. En

27 Ver Keynes (1936) y Stiglitz (2010).

${ }^{28}$ Ver Hodgson (2018, cap. 2). 
este punto critiqué a Dulce Libertad por confiar únicamente en la presión individual como elemento suficiente para contrarrestar los poderosos intereses creados que pueden socavar la democracia o la libertad. Los individuos no son suficientes: las democracias modernas requieren un equilibrio de poderes compensatorios organizados. Pero tu posición en este punto es incluso más débil que la de él.

En tu entusiasmo por la colectivización, la nacionalización y la fuerte intervención del Estado en la economía, subestimas el problema de la concentración de poder en la maquinaria estatal. Personalmente, estoy en favor de alguna propiedad pública. En parte, depende de la naturaleza del servicio y de su papel estratégico en la economía. Se pueden dar buenos argumentos para la provisión pública de ferrocarriles, educación, asistencia a la salud y cierto tipo de vivienda, para mencionar algunos ejemplos. También acepto un papel económico estratégico del Estado. Tiene que haber regulación estatal del sistema financiero para evitar el sobre endeudamiento en los auges y el colapso acumulativo en las recesiones. Como dije a Dulce Libertad, la historia ha demostrado el valor de la empresa pública y de la juiciosa intervención del Estado ${ }^{29}$.

Pero también debemos advertir los peligros de todo esto. Debemos evitar una concentración excesiva del poder económico en las burocracias estatales, así como en las grandes corporaciones. Igual que debemos aceptar una democracia pluralista debemos aceptar una economía pluralista. Es necesario que exista una amplia pluralidad de poderes económicos independientes y autónomos.

Muchos de quienes comparten tu manera de pensar no entienden suficientemente que la pluralidad de poderes e instituciones económicas requiere derechos de propiedad privada y capacidad para intercambiar recursos en los mercados. De lo contrario, el poder residiría en las grandes burocracias estatales. Sin privatización, en la Unión Soviética de Stalin y en la China de Mao se intentó devolver algún poder a las unidades locales. Aunque parte de la toma de decisiones se devolvió con éxito, sin estatus legal ni derechos de propiedad independientes, esa devolución fue limitada y precaria. Se podía revertir fácilmente y trasladarla al centro cuando se juzgaba que la periferia se comportaba mal.

La descentralización efectiva y duradera requiere la devolución de la propiedad legal y del derecho a hacer contratos. Algunos socialis-

${ }^{29}$ Ver Nelson (1981, 2003), Kenworthy (1995), Chang (1997, 2002b), Evans y Rauch (1999), Reinert (2007), Martinez (2009) y Mazzucato (2013).

Revista de Economía Institucional, vol. 2 i, n. ${ }^{\circ} 40$, Enero-junio/2oi 9, PP. ili-i 42 ISSN OI 24-5996/E-ISSN 2346-2450 
tas destacados como Beatrice y Sidney Webb, G. D. H. Cole y Karl Polanyi no lo entendieron ${ }^{30}$.

La abolición o marginación de los derechos de propiedad privada es inviable en una economía dinámica de gran escala. Además, esas medidas llevarían a concentraciones del poder económico que constituyen una fuerte amenaza para la democracia, los derechos y las libertades. En ningún caso histórico de tales concentraciones de poder han sobrevivido una democracia significativa o una libertad adecuada. Por supuesto, también hay ejemplos de capitalismo despótico, de modo que la propiedad privada y los mercados no son garantes de la democracia y la libertad. La propiedad privada y los mercados son condiciones necesarias pero insuficientes para la libertad. La democracia y la libertad necesitan más que propiedad privada y mercados; no obstante, los necesitan.

Aquí tienes un problema. A diferencia de la Izquierda original, te disgustan los mercados. Tony Benn fue un ejemplo clásico: contrapuso la "democracia" a las "fuerzas del mercado" sin advertir que son en parte complementarios y no substitutos factibles. Es típica esta declaración que hizo en la Cámara de los Comunes en 1990: "No comparto la opinión general de que las fuerzas del mercado son la base de la libertad personal". Puedes notar que su uso de la expresión "fuerzas del mercado" demoniza a los "mercados" como poderes impersonales peligrosos, que de algún modo están más allá de la responsabilidad o la agencia humana. De hecho, los mercados son resultados inevitables de una sociedad a gran escala basada en la propiedad privada, con derecho a vender y comprar esa propiedad. Benn defendía una amplia propiedad común en vez de las fuerzas del mercado. Quería libertad y democracia. Pero mientras que la propiedad privada ha existido sin libertad ni democracia, estas nunca han prosperado bajo una propiedad común generalizada ${ }^{31}$.

Numerosos intelectuales académicos siguen proponiendo la abolición de la propiedad privada o de los mercados. Por ejemplo, el economista socialista educado en el Instituto Tecnológico de Massachusetts Michael Albert escribió: "Soy un abolicionista del mercado. Sé que los mercados nos acompañarán durante algún tiempo, pero también sé -o así espero- que con el tiempo los remplazaremos por completo". El economista socialista educado en Harvard Robin Hahnel también defendió la visión de una economía sin mercados: "No creo que los mercados tengan algún papel que cumplir en una economía

${ }^{30}$ Ver Cole $(1917,1932)$, Webb y Webb (1920) y Dale (2010).

${ }^{31}$ La cita es de Hansard (1990). 
verdaderamente deseable [...] nuestra meta a largo plazo debería ser remplazarlos totalmente por algún tipo de planeación democrática".

Los influyentes filósofos marxistas y "realistas críticos" Roy Bhaskar y Andrew Collier apoyaron "una forma de socialismo que no es una economía de mercado ni una economía dirigida ni una mezcla de ambas, sino una extensión genuina de la democracia pluralista en la vida económica”. No dicen cómo funcionaría este sistema sin mercado, particularmente en términos de la organización de una producción compleja a gran escala y de incentivos para trabajar e innovar.

El filósofo socialista John O’Neill pretendió “refutar el argumento en favor de una economía de mercado" y defendió el asociacionismo internacional sin dinero y sin mercado, tal como lo esbozó el filósofo socialista Otto Neurath. O’Neill señaló las limitaciones éticas del mercado, sin detallar una alternativa plausible. Pero aunque los mercados fueran éticamente defectuosos, sin una alternativa viable y humana estamos obligados a tolerarlos. A partir de las experiencias del siglo XX deberíamos haber aprendido que las alternativas de no mercado pueden ser éticamente mucho peores ${ }^{32}$.

Las afirmaciones antes mencionadas son extremas en cuanto proscriben cualquier forma de arreglo de mercado, incluso en los márgenes de una economía por lo demás planificada. Su uso no cualificado del término "mercado" indica una prohibición de todos los intercambios contractuales de bienes de servicios y la total abolición del derecho a vender propiedades, si no la abolición de todos los derechos de propiedad privada. Al poner fin a una economía mixta y suprimir múltiples fuentes económicas de poder compensatorio, esto pondría en peligro la libertad y la democracia.

Existen, por tanto, graves peligros en tu visión no comprobada de una economía dirigida por el Estado. La historia nos dice que puede haber peligros al tratar de llevarla a cabo sin una protección vigilante de los derechos de propiedad en sentido amplio. Consideremos la tragedia chilena de 1973. El marxista Pedro Vuskovic, ministro de Economía de Chile durante el gobierno de Salvador Allende desde 1970 hasta 1972, declaró desde el poder que "el control del Estado está diseñado para destruir la base económica del imperialismo y de la clase dominante poniendo fin a la propiedad privada de los medios de producción”. No aceptó ningún papel del sector privado. Para los socialistas idealistas que ven la propiedad común como el destino humano, él avanzaba por el camino predestinado de la historia. Pero

32 Ver Benn (1979, 1981, 1982, 2000), Albert (2004), Hahnel (2007, p. 1157), Bhaskar y Collier (1998, p. 392) y O’Neill (1998, pp. 176-177).

Revista de Economía Institucional, vol. 2 i, n. ${ }^{\circ} 40$, Enero-junio/20i9, Pp. ili-i 42 ISSN OI 24-5996/E-ISSN 2346-2450 
para los realistas que desean mantener un segmento significativo de empresa privada, esas declaraciones son antiliberales y provocadoras ${ }^{33}$.

Aunque la elección de 1970 fue legal, el gobierno de Allende expropió inconstitucionalmente la propiedad privada sin compensación. En agosto de 1973, la Cámara de Diputados de Chile aprobó una resolución que exigía que el gobierno pusiera fin a las infracciones de la Constitución y acatara las leyes chilenas. El golpe de Estado de Pinochet derrocó al gobierno de Allende en septiembre de 1973. Miles de personas fueron asesinadas y torturadas. Nada justifica la dictadura asesina de Pinochet. Pero los visionarios marxistas de visión nebulosa - con su creencia cuasi religiosa en que las fuerzas históricas estaban de su lado- cumplieron su parte al provocar a los reaccionarios brutales.

A ti te disgusta la mercantilización. A mí también. Te disgusta la avaricia. A mí también. Criticas los mercados por ser impersonales. Pueden serlo. Exaltas la cooperación. Estoy de acuerdo en que es vital para una sociedad saludable. Estoy de acuerdo en que cuando una sociedad intenta reducir todo a un valor monetario, existe el riesgo de que la humanidad pierda su brújula moral y quede espiritualmente desprovista.

Tenemos más acuerdos. A diferencia de von Mises y otros, tú y yo adoptamos una visión históricamente específica del intercambio contractual. Así podemos identificar esferas de actividad-como la familia- que no funcionan con base en contratos comerciales. Los cabeza de familia no se pagan uno a otro cada vez que hacen la limpieza o lavan los platos. Esas cosas se pueden hacer con base en la cooperación y la comprensión mutua. Tú aprecias la diferencia entre contratos legales y cooperación informal. Entiendes que la fraternidad y el altruismo genuino son posibles.

Pero omites un problema crucial: los planificadores soviéticos lo llamaron "la maldición de la escala" 34 . La reciprocidad y la cooperación íntima, cara a cara, en general son viables y suficientes únicamente en comunidades pequeñas. La esfera de la amistad y la cooperación se basa en la familiaridad y en el contacto personal: esto limita el número de personas involucradas. En comunidades pequeñas, la interacción interpersonal puede promover la confianza. La violación de las reglas se puede castigar con la vergüenza, el rechazo o la

33 Cita de Moss (1973, p. 59). Reacciones asesinas asimilares fueron provocadas por el insensato e imprudente levantamiento Espartaquista en Alemania en 1919 (Watt 1969, Hodgson 1977) y por otras aventuras marxistas.

${ }^{34}$ Ver Nove (1983, n. p 75). 
pérdida de reputación. Pero estos mecanismos dependen de grupos relativamente pequeños.

En grupos grandes es imposible conocer a todos. Los mecanismos interpersonales que promueven la confianza y el cumplimiento de las reglas son menos efectivos. Son lanzados a los márgenes y recovecos del sistema. Las sociedades de gran escala deben confiar en los mercados, en la burocracia o en ambos. Tu queja válida sobre la impersonalidad de los mercados se puede aplicar con mayor fuerza a la burocracia. El grave peligro es que el mercado impersonal sea remplazado por una burocracia aún más impersonal.

Los primeros planes comunistas y socialistas para tener propiedades en común eran en general de pequeña escala. En cambio, Marx y Engels supusieron erróneamente que los mecanismos cooperativos que pueden funcionar bien en sociedades de pequeña escala se pueden ampliar fácilmente diez mil veces a la arena nacional, de comunidades de cientos de personas a naciones de millones. La lógica y la experiencia muestran que no se puede. $\mathrm{El}$ problema de $1 / n$ se agrava ${ }^{35}$.

Además de los peligros políticos del poder económico concentrado en manos del Estado, no aprecias los insuperables problemas epistemológicos de reunir todo el conocimiento y la información necesarios para planificar una economía moderna y compleja. Como mencioné en mi carta a Dulce Libertad, igual que algunos defensores de los mercados competitivos, no aprecias las consecuencias del paso de un sistema industrial que produce adminículos a una economía compleja del conocimiento basada en servicios de información y de otro tipo. En dicha economía, es imposible la planificación integral y detallada de tales servicios desde el centro. En vez de ella, el Estado tiene el papel principal en la fijación de estándares de comercio y en la regulación de los mercados, que en gran medida siguen siendo indispensables.

Tú y tus predecesores socialistas han tenido más de 150 años para describir en detalle cómo podría funcionar un socialismo factible. No lo han hecho. En este tema tampoco has aprendido de la experiencia, cuyos resultados han sido catastróficos.

Debido a la falta de un esbozo práctico de un socialismo factible, tus camaradas revolucionarios de Rusia en 1917 y de China en 1949

${ }^{35} \mathrm{E} 1$ problema de $1 / n$ se relaciona con lo que los economistas llaman "el problema del gorrón”. A medida que aumenta el tamaño de la comunidad, este problema se puede agravar. Si el número de personas de una comunidad de trabajo que comparte sus ingresos es $n$, los incentivos individuales para contribuir al producto de la comunidad son muy similares a $1 / n$. A medida que $n$ aumenta se recompensa menos el esfuerzo extra de cualquier individuo, porque el resultado del esfuerzo adicional se comparte entre $n$ personas. 
tuvieron que empezar casi desde cero. Fracasaron. La planificación integral a gran escala sofocó la innovación y llevó a una burocracia aplastante y a recortar la libertad. Con un gran costo humano, estos casos confirmaron lo que los críticos ya sabían, que el socialismo clásico no puede funcionar, al menos mientras mantiene la democracia y la libertad. El resultado fue la muerte de decenas de millones de personas.

E1 siglo XX siguió su curso. Tu tiempo se acabó: se agotaron tus opciones. Mantener el socialismo clásico frente a estos argumentos y estas experiencias es aumentar la irresponsabilidad de tus camaradas anteriores.

Una vez se aborda el problema de imaginar un futuro socialista democrático en sociedades de gran escala, con serios intentos de responder preguntas prácticas sobre cómo se reúne y transmite la información, cómo se producen y distribuyen los recursos y cómo se capacita e incentiva a todos para que trabajen bien e innoven, se entiende que el socialismo democrático (al menos en el sentido clásico de una propiedad pública abrumadora) es inviable en una economía compleja de gran escala. Para que haya dinamismo y eficiencia tienen que haber competencia, mercados y un sector privado grande, así como un Estado. La propiedad privada también es importante por razones políticas, para crear zonas de poder político-económico que puedan contrarrestar la autocracia del Estado.

Una vez se entiende esto, tu juego cambia irrevocablemente. Una vez se entiende que el socialismo clásico no puede funcionar (al menos de manera democrática y humana) hay que buscar alternativas. Una vez se reconoce que la propiedad privada y los mercados son indispensables en las economías modernas de gran escala, hay que aceptarlos, con todos sus defectos. Lo mejor que se puede hacer es aprovechar sus beneficios y minimizar sus efectos nocivos.

La gran marcha de la historia hacia el socialismo queda al descubierto como un mito. El socialismo clásico y la victoria del proletariado desaparecen como íconos. El proletariado ya no es el medio para nuestra liberación. El mito del destino histórico se derrumba. Todos ellos se revelan como dogmas peligrosos.

La historia ya no está de tu lado. Igual que todos los demás en el mundo real, te enfrentas a la confusa tarea de hacer lo que puedas y salir del paso. La extensión de la propiedad pública o privada no es una cuestión de ideología, sino de qué funciona mejor en circunstancias particulares. Recuperemos lo que es viable del naufragio socialista, incluida la búsqueda de justicia social y la reducción de la desigualdad. De lo contrario la nave socialista se hundirá. 
Quizá hayas entendido esto en parte, para abogar por una "economía mixta" como propuso Corbyn al partido laborista británico ${ }^{36}$. Hasta ahora, todo bien. Pero tolerar un sector privado no es lo mismo que defenderlo o reconocer sus virtudes. Mi amigo Dulce Libertad apoya la empresa privada y los mercados. Le pregunté: ¿cuáles son sus límites, y dónde son mejores otras estructuras? Ahora te pregunto: pareces preferir la empresa pública a la privada, pero ¿hay algún límite para este remedio? $\mathrm{O}$ al contrario, ¿hay algunas esferas de actividad que en principio mantendrías privadas? ¿Reconoces las ventajas y la importancia vital de un sector privado sustancial? A menos que tengas respuestas sólidas a estas preguntas, que impliquen la defensa de un segmento sustancial de empresa privada, tu economía mixta es solo un punto intermedio en tu pretendido camino hacia el socialismo pasado de moda: se convierte en una peligrosa pendiente socialista.

Pero después de la costosa experiencia experimental del socialismo en el siglo XX, nuestra única opción aceptable para el futuro previsible es una forma modificada de capitalismo. Las variedades de capitalismo existentes indican que son posibles diferentes destinos. También deberíamos alentar las cooperativas de trabajadores. También necesitamos abordar la importante reforma del sistema financiero, comparando diferentes soluciones institucionales y seleccionando la que mejor funcione. Quizá en algún momento las economías más desarrolladas puedan evolucionar más allá del capitalismo. Pero eso está muy lejos, y no se puede prever para aquí y ahora. Necesitamos experimentar y ver qué funciona.

Al defender la propiedad privada y mantener un papel importante para los mercados (al menos en las sociedades complejas a gran escala) mi posición está de algún modo a la izquierda de la tuya. Pero tú objetas mi descripción de Izquierda y Derecha. Respondes: "el tiempo ha avanzado desde la década de 1790. Las palabras cambian de significado y el uso moderno de 'izquierda' es legítimo”.

¿Pero cuál es este uso moderno? "La Izquierda moderna simboliza el colectivismo y la igualdad" es tu respuesta. Estoy de acuerdo en que la igualdad es importante. Pero has coqueteado con regímenes totalitarios y de partido único que han sacrificado sistemas jurídicos adecuados que podrían haber mantenido iguales derechos legales. Estos regímenes politizaron el proceso judicial y convirtieron la igualdad jurídica en algo nominal en vez de real.

Algunos amigos del régimen chino defienden el sistema bukou en China, que, al dar a las personas un estatus diferente con base en su

${ }^{36}$ Ver BBC News (2016).

Revista de Economía Institucional, vol. 2 i, n. ${ }^{\circ} 40$, Enero-junio/20i9, Pp. ili-i 42 ISSN OI 24-5996/E-ISSN 2346-2450 
ubicación, es una flagrante violación de la igualdad bajo la ley. Además, el grado de igualdad en la distribución del ingreso que se logró en la Unión Soviética de Stalin y en la China de Mao no fue nada impresionante. Los países capitalistas escandinavos son relativamente igualitarios y han mantenido la democracia y la libertad ${ }^{37}$.

Volviendo al colectivismo, este también ha sido el credo de la Derecha. La palabra "fascismo" se deriva del uso simbólico de los fasces de la antigua Roma, cuyas varas unidas significaban fuerza colectiva. El fascismo sometió el individualismo al todo colectivo. De manera similar, el nacionalismo ensalza a la nación sobre el individuo. Si insistes en que el colectivismo es de Izquierda, considera que el fascismo y el nacionalismo se inclinan en la misma dirección colectivista.

A ti y a tus camaradas les gusta el término "democracia". ¿Pero por qué no estás más atento a promover la democracia en China y en otros países en desarrollo? La respuesta puede ser que sospechas de la agenda neoliberal occidental y del "consenso de Washington". Donde los llamado "neoliberales" promueven la democracia, los derechos de propiedad y la privatización reaccionas contra ellos. Donde promueven programas anti-corrupción en países en desarrollo, ves esto como una táctica para privatizar sus economías. He oído a algunos de tus camaradas defender la corrupción en economías en desarrollo como China e India, con base en que "hacen bien las cosas". Señalas que China ha logrado un rápido crecimiento económico, con corrupción y sin democracia ni derechos de propiedad claros.

Pero, en respuesta, China aún tiene un PIB per cápita relativamente bajo. Abundante evidencia sugiere que niveles de desarrollo intermedios y más altos pueden beneficiarse de la democracia, de derechos de propiedad claros y de un sistema legal relativamente independiente. Abundante evidencia también sugiere que la corrupción tiene efectos negativos sobre el crecimiento económico ${ }^{38}$.

Concuerdo contigo en que el Estado cumple un papel estratégico importante tanto en las economías en desarrollo como en las desarrolladas. Pero la democracia, los derechos de propiedad seguros y minimizar la corrupción son también esenciales. Son virtudes en sí mismas, además de necesarias para sostener el dinamismo económico. En tu exagerada reacción contra el liberalismo pro mercado, minimi-

${ }^{37}$ Ver, por ejemplo, Pryor (1973) y Wiles (1974).

${ }^{38}$ Sobre la democracia y el crecimiento económico ver Hodgson (2018, cap. 7) Para estudios que muestran los efectos negativos de la corrupción. ver Shleifer y Vishny (1993), Mauro (1995), Jain (2001), Mo (2001), Aidt (2003) y Pellegrini y Gerlagh (2004). Es vital enfrentar la corrupción privada así como la corrupción pública (Hodgson 2013, cap. 7). 
zas todo esto. En cambio, promueves un estatismo romántico y restas importancia a la competencia y a los mercados. Pero tu estatismo nunca ha proporcionado el grado de igualdad de riqueza y de poder que justamente deseas. En tu exagerada reacción contra el liberalismo pro mercado, subvaloras la evidencia que refuta tu argumento, y abandonas varios principios clave de la Izquierda.

Protestaste contra la intervención occidental en Afganistán, Irak, Libia y Siria. Pero tu oposición general a la acción militar de Occidente te ha llevado a devaluar los ideales occidentales que provienen de la Ilustración. Tu "antiimperialismo" te ha predispuesto contra sus invaluables ideales y principios. Igual que Corbyn, puedes ser un sentimentalista de la revolución de tipo cubano, y aliarte con la Rusia de Putin en su postura postsocialista contra Occidente ${ }^{39}$.

Tu veneración por los grandes monopolios estatales, tu desconfianza de la propiedad privada y las fallas de tus colegas con respecto a la libertad humana te sitúan en la Derecha, en el sentido original de ese término.

En vez de eso, deberías avanzar hacia la Izquierda genuina. Consideremos a Thomas Paine; un hombre de Izquierda que quería mayor igualdad económica, pero dentro del marco de una economía de mercado de propietarios. Él ofrece el mejor camino para que te muevas de la Derecha a una Izquierda más genuina. Las ideas de Paine se deben actualizar y combinar con las de otros liberales sociales, incluidos Thomas H. Green y John A. Hobson.

No se trata simplemente de tomar el lado redistributivo de Paine y minimizar lo demás. Paine defendió la libertad; el tipo de libertad que tantos de izquierda relegaron en el pasado. Esta incluye el derecho a poseer e intercambiar propiedad privada. Paine no quería simplemente quitar a los súper ricos y dar a los pobres. Hoy habla a los que aspiran a ser parte del rango medio de la sociedad, que desean mantener sus pequeños negocios o desarrollar sus capacidades profesionales.

Ellos quieren ser protegidos de las grandes corporaciones y de las burocracias insensibles. Quieren una buena educación secular para sus hijos, para que ellos también puedan lograr algo en su vida y en su carrera. Quieren una decente atención a la salud para enfrentar el infortunio de una enfermedad o un accidente. Aceptan el papel económico del Estado en la provisión de infraestructura y redes de seguridad para los pobres, pero también consideran que la protección de la propiedad y de la empresa es vital.

${ }^{39}$ Ver Corbyn $(2011,2014)$.

Revista de Economía Institucional, vol. 2 i, n. ${ }^{\circ} 40$, Enero-junio/20i9, Pp. ili-i 42 ISSN OI 24-5996/E-ISSN 2346-2450 
A diferencia de tus camaradas, Paine nunca llamó con sarcasmo "pequeño burgueses"o "clase media" a estas personas. Los muy variados aspirantes al rango medio son hoy tus principales electores. Ignóralos a tu riesgo político.

Tu izquierda se agotó. Está en una profunda crisis política en todo el mundo. Los políticos socialdemócratas o laboristas han intentado adaptarse. Algunos abandonaron su compromiso general con la nacionalización. Una minoría decreciente se mantiene fiel al socialismo original en decadencia, para descubrir que hoy en día tiene muy poco arrastre político. Se aferran a él, señalando las crisis y las fallas del capitalismo mientras que se sienten fortalecidos por los dogmas infundados de la "inevitabilidad" del socialismo y del proletariado como "clase universal".

A las versiones más extremas del socialismo no les ha ido mejor. En Gran Bretaña, el partido Unidad de Izquierda acogió una minoría que apoyaba al llamado Estado Islámico en Irak y Siria. Los grupos de extrema izquierda muestran un perenne carácter antidemocrático y no protector de los derechos humanos básicos. Estos resultados no son accidentales. Son el resultado de giros erróneos que tu izquierda dio en el pasado ${ }^{40}$.

Para encontrar una alternativa debes librarte del viejo equipaje que te impide avanzar. El socialismo clásico está muerto. Pero, reanimada como un zombi, la palabra "socialismo" conserva vigencia. Es engañosa para todos y poco atractiva para muchos. Es hora de enterrarla. Debemos encontrar un nuevo lenguaje, con nuevos íconos. Debemos aprender del pasado y mirar hacia el futuro.

\section{REFERENCIAS BIBLIOGRÁFICAS}

Aidt, T. S. (2003). Economic analysis of corruption: A survey. Economic Journal, 113(8), F632-F652.

Abert, M. (2004). Market madness. Znet, [http://zcomm.org/znetarticle/ market-madness-by-michael-albert-1/].

Arrow, K. J. (1962). Economic welfare and the allocation of resources to invention. En R. Nelson (ed.), The rate and direction of inventive activity: Economic and social factors (pp. 609-625). Princeton, NJ: Princeton University Press.

40 Sobre Unidad de Izquierda, ver Jones (2014) y Sommers (2014). Consideremos también la implosión del Partido Socialista de los Trabajadores del Reino Unido (SWP) en 2014 como resultado de su abismal manejo interno de las acusaciones de violación que hicieron algunas mujeres contra un alto funcionario del SWP. El SWP es un muy mal ejemplo derechos humanos básicos y estándares y de justicia. Estos atributos no son accidentales: son congénitos al marxismo (ver capítulos 5 y 6). 
BBC News. (1999). Thatcher stands by Pinochet, [http://news.bbc. co.uk/2/hi/304516.stm].

BBC News. (2016). Jeremy Corbyn outlines labour's vision of a "New Economics”, [http://www.bbc.com/news/uk-politics-36351149].

Benn, T. (1979). Arguments for socialism. Londres: Jonathan Cape.

Benn, T. (1981). Arguments for democracy. Harmondsworth: Penguin.

Benn, T. (1982). Parliament, people and power: Agenda for a free society. Londres: Verso.

Benn, T. (2000). Commanding heights, [http://www.pbs.org/wgbh/commandingheights/shared/minitext/int_tonybenn.html].

Bevins, A. y Streeter, M. (1996). Nelson Mandela: From “Terrorist” to tea with the Queen, The Independent, 8 de julio, [http://www.independent.co.uk/news/world/from-terrorist-to-tea-with-the-queen-1327902 .html].

Bhaskar, R. y Collier, A. (1998). Introduction: Explanatory critiques. En Archer, M. S., Bhaskar, R., Collier, A. et al. (eds). Critical realism: Essential readings (pp. 385-394). Londres y Nueva York: Routledge.

Block, W. (1996). Hayek's Road to serfdom. Journal of Libertarian Studies, 12(2), pp. 339-365.

Bowles, S. y Gintis, H. (2002). The inheritance of inequality. Journal of Economic Perspectives, 16(3), pp. 3-30.

Caldwell, B. J. y Montes, L. (2015) Friedrich Hayek and his visits to Chile, Review of Austrian Economics, 28(3), pp. 261- 309.

Chang, H.- J. (1997). The economics and politics of regulation: A critical survey. Cambridge. Journal of Economics, 21(6), , pp. 703-728.

Chang, H.- J. (2002). Breaking the mould: An institutionalist political economy alternative to the neo-liberal theory of the market and the State, Cambridge Journal of Economics, 26(5), pp. 539-559.

Cole, G. D. H. (1917). Self- government in industry. Londres: G. Bell.

Cole, G. D. H. (1932). The intelligent man's guide through world chaos. Londres: Gollancz.

Corbyn, J. (2011). Foreword. En Hobson, J. A. (1902). Imperialism: $A$ study, reimpresión en facsímil. Nottingham: Spokesman.

Corbyn, J. (2014). Nato belligerence endangers us all, Morning Star, 17 de abril, [http://www.morningstaronline.co.uk/a-972b-Nato-belligerenceendangers-us-all].

Credit Suisse Research Institute. (2012). Credit Suisse global wealth databook 2012. Zurich: CSRI.

Dale, G. (2010). Karl Polanyi: The limits to the market. Cambridge: Polity Press.

Dewey, J. (1916). Democracy and education. Nueva York: Macmillan.

Dewey, J. (1935). Liberalism and social action. Nueva York: G. P. Putnam's Sons.

Dewey, J. (1938). Logic: The theory of enquiry. Nueva York: Holt.

Dewey, J. (1939). Theory of valuation. Chicago: University of Chicago Press.

Evans, K. G. (2000). Reclaiming John Dewey: Democracy, inquiry, pragmatism, and public management, Administration and Society, 32(3), pp. 308.328. 
Evans, P. y Rauch, J. E. (1999). Bureaucracy and growth: A cross-national analysis of the effects of "Weberian" State structures on economic growth. American Sociological Review, 64(5), pp. 748-765.

Finnis, J. (1980). Natural law and natural rights. Oxford: Clarendon Press.

Franklin, J. (2015). Pinochet directly ordered killing on US soil of Chilean diplomat, papers reveal, The Guardian, 8 de octubre, [http:// www.theguardian.com/world/2015/oct/08/pinochet-directly-orderedwashington-killing-diplomat-documents-orlando-letelier-declassified].

Friedman, M. (1976). Reply to Citizen's Committee on Human Rights and Foreign Policy, "Advising Chile", Newsweek, carta al editor, 14 de junio.

Friedman, M. (1991). Economic freedom, human freedom, political freedom. Discurso pronunciado el 1 de noviembre de 1991, [http:// calculemus.org/lect/07pol-gosp/frlect.html].

Fukuyama, F. (2011). The origins of political order: From pre-human times to the French Revolution. Londres y Nueva York: Profile Books y Farrar, Straus y Giroux.

Galbraith, J. K. (1952). American capitalism: The concept of countervailing power. Boston: Houghton Mifflin.

Galbraith, J. K. (1962). American capitalism: The concept of countervailing power, 3rd ed. Boston: Houghton Mifflin.

Galbraith, J. K. (1969). The new industrial State. Harmondsworth: Penguin.

Hansard. (1990). Parliamentary debates, 22 de noviembre de 1990, columna 485, [https://www.publications.parliament.uk/pa/cm199091/ cmhansrd/1990-11-22/Debate-6.html].

Hayek, F. A. (1948) Individualism and economic order. Londres y Chicago: George Routledge y University of Chicago Press.

Hayek, F. A. (1960). The Constitution of liberty. Londres y Chicago: Routledge y Kegan Paul, y University of Chicago Press.

Hayek, F. A. (1973) Law, legislation and liberty, vol. 1: Rules and order. Londres: Routledge y Kegan Paul.

Hayek, F. A. (1979) Law, legislation and liberty, vol. 3: The political order of a free people. Londres: Routledge y Kegan Paul.

Hahnel, R. (2007). The case against markets, Journal of Economic Issues, 41(3), pp. 1139-1159.

Heller, M. A. (2008). The gridlock economy: How too much ownership wrecks markets, stops innovation, and costs lives. Nueva York: Basic Books.

Hodgson, G. M. (1977). Socialism and parliamentary democracy. Nottingham: Spokesman.

Hodgson, G. M. (2013). From pleasure machines to moral communities: An evolutionary economics without homo economicus. Chicago: University of Chicago Press.

Hodgson, G. M. (2015). Conceptualizing capitalism: Institutions, evolution, future. Chicago: University of Chicago Press.

Hodgson, G. M. (2018). Wrong turnings. How the left got lost. Chicago: Chicago University Press.

Hoppe, H.-H. (1994). F. A. Hayek on government and social evolution: A critique. Review of Austrian Economics, 7(1), pp. 67-93.

Ingham, G. (2004). The nature of money. Cambridge: Polity Press. 
Ingham, G. (2008). Capitalism. Cambridge: Polity Press.

Jain, A. K. (2001). Corruption: A review, Journal of Economic Surveys, 15(1), pp. 71-120.

Jones, B. (2014). Mission creep on the anti-war left, National Secular Society, 19 de noviembre, [http://www.secularism.org.uk/blog/2014/11/ mission-creep-in-the-anti-war-left].

Kenworthy, L. (1995). In search of national economic success: Balancing competition and cooperation. Thousand Oaks, Ca., y Londres: Sage.

Keynes, J. M. (1930). A treatise on money, vol. 1: The pure theory of money. Londres: Macmillan.

Keynes, J. M. (1936). The general theory of employment, interest and money. Londres: Macmillan.

Klaus, V. (2007). Freedom, not climate, is at risk. Financial Times, 13 de junio, [https://www.ft.com/content/9deb730a-19ca-11dc-99c5000b5df10621].

Klein, N. (2007). The shock doctrine: The rise of disaster capitalism. Nueva York: Henry Holt.

Letelier, O. (1976). The Chicago boys in Chile: Economic freedom's awful toll, The Nation, 28 de agosto [http://www ditext.com/letelier/ chicago.html].

Marshall, A. (1920). Principles of economics: An introductory volume, 8th ed. Londres: Macmillan.

Martinez, M. A. (2009). The myth of the free market: The role of the State in a capitalist economy. Sterling, Va.: Kumarian Press.

Mauro, P. (1995). Corruption and growth, Quarterly Journal of Economics, 110(3), pp. 681-712.

Mazzucato, M. (2013). The entrepreneurial State: Debunking public vs. private sector myths. Londres y Nueva York: Anthem.

Minsky, H. P. (1982). Can "it" happen again? Essays in instability and finance. Armonk, NY: M. E. Sharpe.

Minsky, H. P. (1986). Stabilizing an unstable economy, New Haven, Conn.: Yale University Press.

Mo, P. H. (2001). Corruption and economic growth, Journal of Comparative Economics, 29(1), pp. 66-79.

Moore, B., Jr. (1966). Social origins of dictatorship and democracy: Lord and peasant in the making of the modern world. London: Allen Lane.

Moss, R. (1973). Chile's Marxist experiment. Nueva York: John Wiley.

Nelson, R. R. (1959). The simple economics of basic scientific research. Journal of Political Economy, 67(3), pp. 297-306.

Nelson, R. R. (1981). Assessing private enterprise: An exegesis of tangled doctrine. Bell Journal of Economics, 12(1), pp. 93-111.

Nelson, R. R. (2003). On the complexities and limits of market organization. Review of International Political Economy, 10(4), pp. 697-710.

North, D. C., Wallis, J. J. y Weingast, B. R. (2009). Violence and social orders: A conceptual framework for interpreting recorded human history, Cambridge: Cambridge University Press.

Nove, A. (1983). The economics of feasible socialism. Londres: Allen and Unwin. 
O'Neill, J. (1998). The market: Ethics, knowledge and politics. Londres y Nueva York: Routledge.

Pagano, U. (2014). The crisis of intellectual monopoly capitalism. Cambridge Journal of Economics, 38(6), pp. 1409-1429.

Pellegrini, L. y Gerlagh, R. (2004). Corruption's effect on growth and its transmission channels, Kyklos, 57(3), pp. 429-456.

Piketty, T. (2014). Capital in the Truenty- First Century. Cambridge, Mass.: Belknap Press.

Polanyi, K. 1944. The great transformation: The political and economic origins of our time. Nueva York: Rinehart.

Pryor, F. L. (1973). Property and industrial organization in communist and capitalist nations, Bloomington: Indiana University Press.

Reinert, E. S. (2007). How rich countries got rich... And why poor countries stay poor. Londres: Constable.

Rifkin, J. (2014). The zero marginal cost society: The internet of things, the collaborative commons, and the eclipse of capitalism. Nueva York y Londres: Palgrave Macmillan.

Rodrigues, J. (2012). Where to draw the line between the State and the market? Journal of Economic Issues, 46(4), pp. 1007-1033.

Ryan, A. (1995). John Dewey and the high tide of American Liberalism. New York: Norton.

Samuelson, P. A. (1947). Foundations of economic analysis. Cambridge, Mass.: Harvard University Press.

Shleifer, A. y V., Robert W. (1993). Corruption, Quarterly Journal of Economics, 108(3), pp. 599-617.

Schliesser, E. (2010). Friedman, positive economics, and the Chicago boys. En Emmett, R. B. (ed.). The Elgar companion to the Chicago school of economics (cap. 14, pp. 175-195). Cheltenham, Mass.: Edward Elgar.

Smith, A. (1759). The theory of moral sentiments; or, an essay towards an analysis of the principles by which men naturally judge concerning the conduct and character, first of their neighbours, and afterwards of themselves. Londres y Edinburgo: Millar y Kincaid and Bell.

Sommers, J. (2014). Islamic State's “progressive potential” as "stabilising source" debated by New Left Unity Party, The Huffington Post, 17 de noviembre, [http://www.huffingtonpost.co.uk/2014/11/17/islamicstate-left-unity_n_6171252.html].

Stiglitz, J. E. (2010). Freefall: America, free markets, and the sinking of the world economy. Nueva York: Norton.

Von Mises, L. (1949). Human action: A treatise on economics. Londres y New Haven, Conn.: William Hodge y Yale University Press.

Von Mises, L. (1981). Socialism: An economic and sociological analysis, Indianapolis: Liberty Classics.

Von Mises, L. (1985). Liberalism in the classic tradition, trans. Irvington, NY: Foundation for Economic Education.

Watt, R. M. (1969). The kings depart: The tragedy of Germany: Versailles and the German Revolution. Londres: Weidenfeld and Nicholson.

Webb, S. J. y Webb, B. (1920). A Constitution for the Socialist Commonwealth of Great Britain. Londres: Longmans Green. 
Wiles, P. J. D. (1974). Distribution of income: East and West, Ámsterdam: North- Holland.

Wray, L. R. (2012). Modern money theory: A primer on macroeconomics for sovereign monetary systems. Londres y Nueva York: Palgrave Macmillan. 